will entirely fill up, and, indeed, at the present time I am not sure that the gap does actually extend through into the nasal cavity.

CASE 5.- This, the last of the series, was an infant aged eight months, who was sent to me by Mr. Parsons of Wimbledon. Her cleft involved the soft palate and the posterior third of the hard palate (Fig. 5). I operated on

FIG. 5.

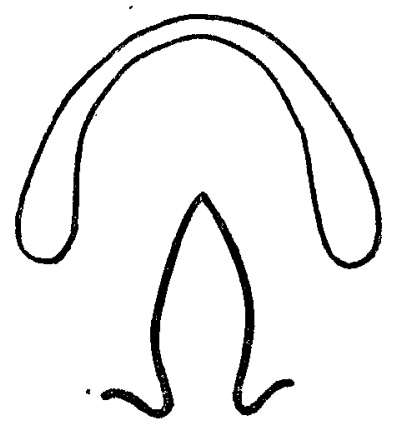

Cleft of soft and of back of hard palate.

er on July 10th, and she was taken home a fortnight later with perfect union even to the tip of the uvula. This was the youngest age-eight months-at which I have ever operated on a cleft which implicated the hard palate, though I have successfully dealt with clefts of the soft palate at an earlier period.

It will be, I think, an interesting and instructive element in the discussion if an expression of opinion is obtained as to what is the best time for endeavouring to close a cleft $(a)$ in the soft palate, and $(b)$ in the soft and the hard palate of a healthy child. For my own part I am getting earlier and earlier with $\mathrm{my}$ operations and for this advance I am much indebted to an article written by Mr. Clutton. The fourth patient was only just two years old when I operated on her couplete cleft. When her father wrote to me a few days before the operation he said "She is now two years old, and as far as we can judge her speech will be affected by the cleft." He hit the nail upon the head. If the speech is to be improved to the utmost the mouth must be roofed in at the very earliest moment. For a soft palate, the child being in good health, the time for operating is somewhere in the first six months, I think. For a hard and soft palate together, it is, I think, in the second year, but I should not be surprised to hear that it may safely be shifted to a still earlier period. It will be noticed that in none of these cases have I suggested the division of the operation into two stages-one for the hard and the other for the soft palate. I used formerly to practise that method in certain difficult cases, but I have now given it up. It is full of disadvantages, and I do not find that it possesses any merit to counterbalance them.

Great Cumberland-place, W.

\section{TWO CASES OF LYMPHADENOMA PRESENTING UNUSUAL SYMPTOMS, WITH POST-MORTEM EXAMINA- TIONS AND COMMENTS THEREON.}

By STEPHEN MACKENZIE, M.D. ABERD., F.R.C.P. LoxD., PHYSICIAN TO, AND LECICRER ON MEDICINE AT, THE LONDON HOSPITAL.

THE two cases about to be related present some unusual features, which in the first were fully explained by the result of the necropsy. They have sufficient interest and importance to appear to me to be worthy of being placed on record.

CASE 1.-A man aged twenty years was on Oct. 30th, 1895, admitted into the London Hospital, under my care, for lymphadenoma. (The notes of the case were taken by Dr. R. M. Going, clinical clerk.) There was no gout, rheumatism, or tuberculosis in the patient's family, and no history or suspicion of syphilis. The present illness began on Sept. 11th, 1895, with acute lumbar pain, which gradually extended first to the right and subsequently to the left sciatic region. About the end of September he was admitted into St. 'Thomas's Hospital, under the care of Dr. Sharkey, for "double sciatica." At this time he had some pyrexia. He remained in hospital abont a fortnight and then discharged himself. After this the pain extended to the abdomen, and Dr. F. H. Davies of Camberwell, his medical attendant, believed he could detect a tumour in that region. I was called in consultation and advised his removal to hospital. Since the commencement of his illness there had been increasing weakness, causing inability to stand, copious night sweats, and numerous attacks of slight epistaxis. On admission to hospital he had an anxious expression, marked anæmia and emaciation, dorsal decubitus, and acute lumbar pain, which was worse on sitting up. The pulse was 120 , the respiration 38 , and the temperature $102^{\circ} \mathrm{F}$. There was a large oval swelling under, and in front of, the middle of the right sterno-mastoid, evidently a mass of enlarged glands. There were also enlarged glands in both supra-clavicular regions, at the left angle of the lower jaw, and in both inguinal regions. They were painless, well-defined, and freely movable under the skin. There was a large patch of discoloured skin over the eacral region, tender to the touch, and giving a somewhat boggy feeling; a sinus situated over the lett posterior superior iliac spine seemed to communicate with it. The left ankle an. foot were œdematous, but there was no cedema of the thigh or thrombosis of the saphenous vein; the left $1+g$ could not be raised by the patient from the bed, but it could be rotated. The extensor muscles of both legs were extremely atrophied, and there was marked tenderness of the calves, but no tenderness over the sciatic nerves. The right knee-jerk was exaggerated, the left being only just present; ankle-clonus was present on the right but not on the left side; the right plantar reflex was well-marked, and the left was only just present. Sensation to touch and pain was normal, but to heat and cold it was absent below the right knee and in the lower half of the left leg. The abdomen was somewhat distended and was tympanitic all over, and, though easy to examine, no tumour could be felt. Nothing abnormal could be felt per rectum. The liver was slightly enlarged. The spleen appeared to be enlarged on percussion, but it could not be felt below the costal margin. There was marked retraction of the second intercostal space to the right of the sternum, with bronchial breathing and bronchophony, but no dulness. No other signs of consolidation were observed. There was some odema at the base of both lungs. The patient had reflex incontinence of urine (when he fel a desire to micturate he conld not restrain it). No albumin was present in the urine. No changes were detected with the ophthalmoscope. Examination of the blood gave the following results. On Nov. 4th the red corpuscles amounted to 42.4 per cent. and the hæmoglobin to 58 per cent. ; on the 11 th the former were 37 per cent. and the latter 35 per cent. ; and on the 16 th they were 22 per cent. and 30 per cent. respectively. There was no increase of white corpuseles. The treatment consisted in the exhibition of gradually increasing doses of liquor arsenicalis (four minims to fifteen minims thrice daily). The pyrexia continued, and the patient gradually lost strength. On Nov. 2nd he complained of "soreness of the throat" and difficulty in swallowing; nothing abnormal could be seen on laryngoscopic examination; the difficulty in swallowing increased till liquid could only be taken. The oedema of the lungs increased, diarrhoea developed, the right foot became cedematous, the temperature gradually fell, and the patient died on the eighteenth day after admission and nine weeks after the commencement of the illness.

Necropsy.-The post-mortem examination was made by Dr. Schorstein, whose careful and complete notes are condensed below. The body was much wasted. A distinct abdominal tumour was felt. There was irregular wasting of the muscles of the thighs, especially the left; slight com: parative wasting of the muscles of the left arm was also observed, but no wasting of the hands or feet. There were large masses of glands above both clavicles and in the groins. The upper lobe of the left lung was bound down by old adhesions, none being present on the right; both pleuræ contained some yellow serous fluid. A large mass of matted glands surrounded the right bronchus and pressed chiefly on the branches going to the middle and lower lobes, which were largely collapsed. The rest of the lungs was odematous. The left external iliac vein was partially invaded by the growth, and a small thrombus of dark colour lying along the outer side of the vessel an inch and a lualf long was contained 
in it. The lumen was diminished, but no actual blocking of either external iliac vein was present. A large glandular mass extended along the aorta from the diaphragm to the pelvis and invaded the sacrum. The whole of the lumbar nerves on both sides, and all the sacral nerves as they issued from the foramina, were surrounded and infiltrated by the growth. Both psoas muscles were invaded by the growth and the left was much atrophied. On the right side the growth extended back between the transverse processes of whe second, third, and fourth lumbar vertebræ, invading the erector spinæ muscle, and it extended along the nerves into the spinal canal, forming on the posterior part of the bodies of the second to fourth lumbar vertebræ, slightly to the right of the middle line, a protuberant mass one-sixth of an inch in elevation, lying beneath the dura mater, pressing it backwards, and pressing on the right side of the cauda. The spinal cord seemed to be normal on section to its lowest limits. The cauda was slightly pressed upon by the growth within the canal, but all the nerves below the first lumbar were surrounded by growth and involved after their exit through the anterior foramina. The pelvic mass of new growth invaded the sacrum and both sacro-iliac joints. The left upper angle of the sacrum was especially involved, and the growth formed a mass in the sacrum, left sacro-iliac joint, and adjoining portion of the ilium, being extremely soft, and breaking down on the slightest pressure. With this a sinus over the posterior superior spine of the ilium communicated, and there was a small bedsore over the lower part of the sacrum. At the upper part of the abdominal mass the growth formed a ring, completely surrounding the lower part of the osophagus where it joins the cardiac and of the stomach. The mass pressed upon the csophagus and partly invaded its outer wall, but the mucous membrane was quite intact. The mesenterio glands were all enlarged. The spleen weighed $10 \mathrm{oz}$. and was soft, natural in colour, and free from growth. The liver weighed $4 \mathrm{lb} .1 \mathrm{oz}$; the central veins were more full than natural, being otherwise normal. The remaining organs presented no important changes. The growth on section was yellowish-white, very soft, and dotted with hæmorrhages, small in size, and little masses of black pigment. Under the microscope there was seen very little reticulum, forming large meshes, and between the meshes there were closely packed masses of small round cells with badly defined nuclei.

Pemarks. - When I first saw tlis patient with Dr. Davies on Oct. 23rd he gave me the history of the "double sciatica"; he told me that the patient since being under his observation had had a temperature averaging about $102^{\circ} \mathrm{F}$., and he thought he had detected a mass in the abdomen. On the occasion of my visit neither of us could feel it. A day or two before my visit enlargement of the glands on the right side of the neck was detected. examined the patient carefully all over, and found that there was pain on movement of the lower extremities, especially the left, but at that time no obvious weakness ; at least, the pain caused by movement appeared to account for its limitation. The skin over the sacrum was red, tender, and cedematous. I was impressed with the great pallor of the patient, and this, together with his high temperature, which had persisted for some time without any satisfactory explanation, as well as the attacks of epistaxis, led me to express an opinion that he was probably suffering from some grave disease of the blood. The enlarged glands in the neck, which were firm and covered by healthy skin, appeared to supply the key-note to the case. With some diffidence I expressed an opinion that it would prove to be one of lymphadenoma, and I suggested that the pain in the lower extremities might be due to invasion of the cord or nerves by a growth of this nature. I offered to take the patient into the hospital under my care in order that he miolnt have the benefit of better nursing and treatment than lie could receive at home. When he came to the hospital, seren days later, the disease was more advanced. The glandular swellings now involved the left side of the nock and both inguinal regions, and their characters were of a pronouncedly lymphadenomatous nature. The examination of his blood showed a high degree of anæmia without any increase of white corpuscles. He now had oidema of the left foot and ankle, wasting of the extensor muscles of the thighs, and tenderness of the calves. The left knee-jerk was almost abolished, whilst on the right side the knee-jerk was exaggerated and ankle-clonus present. The careful observations of Dr. Going further showed that whilst sensation to touch and pain was not altered he had lost thermic sensibility in the lower half of the left leg and below the knee in the right. The condition of the skin over the sacrum appeared to be due to a bedsore produced before I first saw him. The liver was found to be slightly enlarged. With these additional observations $I$ was able to reaffirm my original diagnosis with greater confidence-viz, that the patient was suffering from lymphadenoma, and that the new growth involved the spinal cord or nerves of the lower extremities. As to which of these the paralysis of the legs was due I had some doubts; but the tenderness of the muscles, and in a degree the sensory disturbances, made me feel the difficulty in excluding the nerves. The disease rapidly progressed, the only new symptom arising being dysphagia. The voice was natural, and laryngoscopic examination showed no disease as far as the level of the larynx. I conjectured, therefore, at the bedside that it was due to pressure on the cesophagus by lymphadenomatous growth. The post-mortem examination verified the diagnosis to a degree which I wish were my usual experience. There was an extensive new growth forming a large solid tumour behind the attachment of the mesentery, extending from the level of the third lumbar vertebra downwards into the pelvis. It involved the posterior part of the left ilium and ala of the sacrum, invading both ilio-sacral joints, and the sinus detected during life over the posterior superior spine of the ilium extended down to the diseased joint. The spinal canal was invaded by the disease. The spinal cord was not actually compressed, but the cauda equina was. Another mass pressed upon the termination of the csophagus in the cardiac orifice of the stomach, but the stomach was not infiltrated. Another mass involved the roots of the lungs and by pressure on the right produced collapse of the middle and lower lobes of that lung. The lymphatic glands of the neck and groins were affected. The liver and spleen, though enlarged, had no new growth in them. The growth, examined microscopically, proved to be lymphadenoma. The diagnosis was thus confirmed in every particular. The only important additional revelation was the growth at the roots of the lungs, producing some collapse of the right lung. This might have been detected, but the patient was so weak, and morements caused him so much pain, that the back of the chest was not examined during the last week of his life. The physical signs in the right intercostal space afforded some grounds for a diagnosis of this lesion. 'The accuracy of Dr. Davies's observation earlier in the case of an abdominal tumour was also established; but, probably owing to distension of the intestines, this could not be felt later. The most unusual feature of the case was the invasive character of the growth. I do not remember to have previously met with a case in which the spinal cord was penetrated by a lymphadenomatous growth from without, and it is certainly very unusually recorded in the literature of the subject. But, though the spinal canal was penetrated, the cord was not actually involved in the growth either by infiltration or pressure ; at least, the cord was not in any way flattened, as it would have been had it been subjected to any degree of pressure. The tumour, when its bloodvessels contained circulating blood, would, of course, have been of larger dimensions and may have touched the cord, but not so as to compress it to a degree to give rise to symptoms. The pain, wasting, weakness, and anæesthesia must therefore be referred to pressure on the cauda equina and the nerves. The odemit of the lower extremities was partly due to pressure upon and (on the left side, where the oedema commenced) invasion of the external iliac vein, where a thrombus was found, though the lumen of the vein was not entirely occluded. No doubt cardiac feebleness from his exhausting febrile disease, and loss of movement in the limbs, were contributory factors. The invasion of the sacro-iliac joint was also an unusual feature of the case, as well as the inflammation of the skin over the sacrum due to implication of the posterior branches of the sacral nerves. The inability to raise the left thigh whilst power of rotation remained is probably explained by the direct implication of the psoas muscle. The disease ran a much more rapid course than is usual in lymphadenoma, illustrating both in its course and invasive characters the high degree of malignancy to which this disease may attain, and is in contrast to the almost chronic characters which some cases of lymphadenoma present. In this respect, as well as in its histological characters, lymphadenoma approaches so closely to the sarcomata that it is regarded by many pathologists as a variety of sarcoma-viz., lympho-sarcoma. 
CAsE 2. - A man aged fifty-three years was on March 20th, 1895, transferred to my care by my colleague, Mr. J. McCarthy. The patient complained of weakness, wasting, and pain in the "inside." The following notes are reduced from the records of Messrs. H. Innes and H. F. Tod. The patient's father was gouty, but there did not appear to have been any other tendency to disease in the family. He himself had been a hard-working man, a moderate drinker in recent years, but at one time took stimulants rather freely. He was the father of eleven children all of whom were healthy. He had always been neurotic. He had suffered from gonorrhœa thirty years before, but had never had syphilis. He had had a "slight touch of rheumatism, which was more of a sciatica," in both legs four months previously. It would begin about 4 o'clock in the afternoon and last till about $2 \mathrm{~A}$.M. the next morning. The pain was excruciating, and he could hardly walk. $\mathrm{He}$ had suffered from "winter cough" the previous three years. His present illness began in the previous November with pain in the stomach, where he had a sense of weight and a feeling of "wind," which were increased by food and towards evening. His appetite was good at that time and he did not vomit. His symptoms continued in spite of treatment, and he noticed that he was losing flesh. For some years he had had some vaso-motor functional disorder in his hands and feet, not amounting to Raynaud's disease. On admission he said that since November he had not been able to lie on his left side on account of pain. He could not sleep at night owing to pain and a sense of weight in his stomach. He was anæmic, with a yellowish tint of the skin, which was dry, harsh and furfuraceous. The veins of the neck pulsated. He said that the week before last the calves of his legs swelled up and had been puffy occasionally since. The tongue was slightly deflected to the right, and was dry and coated with white fur. He had no appetite; the bowels were regular; the abdomen was distended and was tympanitic in front and somewhat dull in the flanks. He complained of pain, which was most marked in the epigastrium, but extended into the right and left hypochondria. There was tenderness on pressure, especially in the flanks; there were borborygmi; but no tumour was detected. The liver extended from the sixth rib to a little below the costal margin. The spleen was enlarged, extending from the seventh rib to some distance below the ribs, where it could be felt to have a rounded edge. The stomach resonance extended well up into the thorax. The pulse was 93 ; the arteries were somewhat tortuous, but tension was not increased. The apexbeat was in the fifth space and feeble; dulness was lost from stomach resonance. There was no bruit. No abnormal signs were detected in the lungs beyond a few crepitant râles at the bases posteriorly. There were numerous enlarged glands in the neck, extending from the lobule of the ear to the supra-clavicular fossa on each side, but larger on the left side than the right. They were hard, and matted together when large, but when small isolated and movable; they varied from the size of a horse-chestnut to that of a pea. There were enlarged glands with the same characters in both axillæ and both groins. They were not tender at any part. The first glandular enlargement had been noticed seven years ago on the left side of the neck, and the glands had been increasing in size and extending in range since then in the neck, but he had not noticed them elsewhere. No abnormal signs were observed in the fundi. The temperature was normal, and no albumin was present in the urine. The knee-jerks were present. The patient could walk, but became breathless on exertion. He had lost much flesh lately. The blood when examined a few days later showed 76 per cent. of red corpuscles; there was no increase of white corpuscles, which in eosin- and logwood-stained specimens showed some varieties, but no one kind was predominant. The progress of the case may be briefly summarised as follows. Wdema of both feet appeared, extending to the legs, and later to the back. The urine remained free from albumin to the end; the quantity slightly diminished, but the specific gravity was within the normal range. The temperature was usually near to the normal, but was slightly raised at the close. Complete anorexia became established and was attended with some nausea but no vomiting. He suffered a good deal of pain and discomfort in the stomach. Examination of the blood at a later period showed 60 per cent. of corpuscles, the proportion of white to red being 1 in 120 and one week before his death the red corpuscles amounted to 89 per cent. and the hæmoglobin to 54 per cent.- there was 1 white corpuscle to 100 red corpuscles. Cough and some breathlessness developed; the physical signs of bronchitis were present, and later there was evidence of basic cedema. He died on May 13th. The treatment consisted of the administration of arsenic (ten minims of Fowler's solution three times a day), washing out the stomach every second day, and chloral and bromide of potassium for sleeplessness. Tabloids of supra-renal capsule were tried for some days, one being taken after each meal and one at bedtime. They seemed to increase the nausea, and when the patient took them his temperature began to rise and become remittent. As they did not appear to exercise any favourable influence they were discontinued.

Necropsy.-A post-mortem examination was made on May 14th, 1895. The following notes were taken by Dr. Bertrand Dawson. In the abdomen a hard, dense, and. whitish tissue was adherent to the bodies of the vertebro. It was chiefly situated in the upper part of the abdomen, but extended in smaller amount as far down as the bifurcation of the aorta. The growth above was adherent to the posterior aspect of the stomach, and this viscus was immorably fixed ; it also surrounded the pancreas, which could not be separated from it. Many enlarged glands were buried in this dense tissue. On cutting into this mass the section resembled scirrhus, but a careful examination of several microscopic sections showed it to be nothing but dense fibrous tissue surrounding enlarged glands. Chains of enlarged glands lay along the curvatures of the stomach. The mesenteric glands were also enlarged. The above growth closely encircled the supra-renal capsules, which could not be separated from it, but the latter were quite healthy, as were also the kidneys. The spleen was much enlarged, weighing twenty-one ounces. On section it showed many small white nodules which were typically lymphaderomatous. As regards the liver the glands in the portal fissure were much enlarged, but there was no infiltration of the organ. There were old adhesions of the pleuræ on both sides of the chest. The bronchial glands were a little enlarged. Microscopic section showed the usual appearance of lymphadenoma.

Remarks. There are several points of interest in Case 2 which was treated previously to Case 1 , but I couple it with the former on account of the patient having suffered from pain in both legs, which was thought to be "sciatica." Lymphadenomatous growth was found adherent to the bodies of the vertebræ as low down as the bifurcation of the aurta. Attention was not particularly directed to this part at the necropsy, but in the light of the subsequent case (Case 1) I regret that more care was not given to the examination of the sacral nerves, which may ha:e been compressed by growth which did not attract observation. The case in most respects exemplified the usual course of this disease-viz., olandular enlargement, limited for a long time to the neck, and then later generalisation. In this case the spleen hat lymphadenomatous growths in its interior, whilst in Case 1 none were present. There was one further feature calling for remark - the predominance of gastric symptoms. It happened that when this patient was in the hospital I had at the same time a case of leucocythrmia as well as one of pernicious anæmia. I made the three cases the subject of a clinical lecture, instituting a comparison and a contrast between the three diseases. In com menting on the case of lymphadenoma I drew attention to the gastric symptoms and discussed the possibility of there being cancer of the stomach. I remarked, however, that whilst the diagnosis of cancer of the stomach would explain the pain, nausea, complete anorexia, and the wasting and anæmia, it would not account for the generalised lymphatic enlargement. At the post-mortem examination the appearance of the stomach made all present suspicious that there was scirrhus of that organ, but careful examination showed that the infiltration which fixed the viscus was lymphadenomatous growth with an extreme amount of over-growth of fibrous tissne. Both cases were treated with arsenic, but without benefit, though in a very small minority of cases the drug undoubtedly appears to exercise an almost specific influence. I know of no criterion by which the cases in which the treatment will succeed can be determined, but it should certainly, in spite of many failures, be tried in all cases. The non-success of the supra-renal capsule extract should not discourage other attempts to try this remedy. The disease was very far advanced when it was prescribed. The suggestion of its ase came from Dr. Oliver of Harrogate, who one day accompanied Dr. Ralfe on his visit when he was in charge of my wards.

Cavendish-square, $W$. 